\title{
Fire-mediated germination syndromes in Leucadendron (Proteaceae) and their functional correlates
}

\author{
Rosemary J. Newton ${ }^{1}$ (D - Berin D. E. Mackenzie ${ }^{2,3} \cdot$ Byron B. Lamont $^{4} \cdot$ Pablo Gomez-Barreiro $^{1} \cdot$ Richard M. Cowling ${ }^{5}$. \\ Tianhua $\mathrm{He}^{4}$
}

Received: 1 July 2020 / Accepted: 15 May 2021 / Published online: 23 June 2021

(c) The Author(s) 2021

\begin{abstract}
A mechanistic understanding of fire-driven seedling recruitment is essential for effective conservation management of fire-prone vegetation, such as South African fynbos, especially with rare and threatened taxa. The genus Leucadendron (Proteaceae) is an ideal candidate for comparative germination studies, comprising 85 species with a mixture of contrasting life-history traits (killed by fire vs able to resprout; serotinous vs geosporous) and seed morphologies (nutlets vs winged achenes). Individual and combined effects of heat and smoke on seed germination of 40 species were quantified in the laboratory, and Bayesian inference applied to distinguish biologically meaningful treatment effects from non-zero, but biologically trivial, effects. Three germination syndromes were identified based on whether germination was dependent on, enhanced by, or independent of direct fire cues (heat and smoke). Seed storage location was the most reliable predictor of germination syndromes, with soil-stored seeds c. $80 \%$ more likely to respond to direct fire cues (primarily smoke) than canopy-stored seeds. Notable exceptions were L. linifolium, with an absolute requirement for smoke to germinate (the third serotinous species so reported), and two other serotinous species with smoke-enhanced germination. Nutlet-bearing species, whether serotinous or geosporous, were c. $70 \%$ more likely to respond to fire cues than winged seeds, but there was no evidence for an effect of phylogeny or persistence strategy on germination. This comprehensive account of seed germination characteristics and identification of germination syndromes and their predictors, supports propagation, conservation and restoration initiatives in this iconic fynbos genus and other fire-prone shrubs with canopy or soil-stored seeds.
\end{abstract}

Keywords Bayesian inference $\cdot$ Heat $\cdot$ Serotiny $\cdot$ Smoke $\cdot$ Soil seed bank

Communicated by Edith B. Allen.

Rosemary J. Newton, Berin D.E. Mackenzie and Byron B. Lamont contributed equally and are first authors.

Rosemary J. Newton

r.newton@kew.org

1 Conservation Science, Royal Botanic Gardens Kew, Wakehurst, Ardingly, West Sussex RH17 6TN, UK

2 Science Division, NSW Department of Planning, Industry and Environment, Locked Bag 5022, Parramatta, NSW 2124, Australia

3 Centre for Ecosystem Science, University of New South Wales, Kensington, NSW 2052, Australia

4 Ecology Section, School of Molecular and Life Sciences, Curtin University, PO Box U1987, Perth, WA 6845, Australia

5 Department of Botany, Nelson Mandela Metropolitan University, PO Box 7700, Port Elizabeth 6000, South Africa

\section{Introduction}

Sclerophyll shrublands, called fynbos, are the predominant vegetation type in the biodiverse Cape Floristic Region of South Africa (Bergh et al. 2014). As is the case for vegetation types in other Mediterranean-type regions of the world, fynbos is highly fire-prone (Rundel et al. 2016). Wildfires usually occur during the dry summer-autumn period and have a mean return interval of 10-20 years (Kraaij and van Wilgen 2014). In addition to periodic disturbance by fire, fynbos is characterised by nutrient-poor soils and a Mediterranean-type climate with wet winters and dry summers (Rundel et al. 2016). Fynbos species possess a variety of life-history traits that enable fire survival and consequent persistence in the landscape (Kraaij and van Wilgen 2014), and the origin of fire-adapted traits here can be traced back to at least 90 million years (Lamont and $\mathrm{He} 2012$; He et al. 2016). Most plant species in fynbos, as in other fire-prone 
vegetation, maintain some form of persistent seed bank that is stored in either the canopy (serotiny) or the soil (geospory) and is stimulated to be released and/or germinate in response to fire (Enright et al. 2007; Keeley et al. 2011). These adaptations take advantage of the optimal conditions for seedling recruitment in the postfire environment, and the origin of many can be traced back to the 'fiery' Cretaceous (Lamont et al. 2019).

Research so far concerning fire-cued germination has concentrated on the role of direct fire cues such as heat pulses, charred wood, ash and smoke in inducing germination of geosporous species (Newton et al. 2006; Moreira et al. 2010; Downes et al. 2015; Hall et al. 2017). Less attention has been given to the indirect effects of fire, including changes in chemical and nutrient availability in soil following a fire that promote germination (Pons 1989; Preston and Baldwin 1999), soil water changes (Pérez-Fernández et al. 2000), or widened diurnal surface temperatures due to the reduced cover (Brits 1987; Santana et al. 2013), for example. Few studies consider both independent and combined effects of multiple fire-related and environmental cues that alleviate dormancy and/or promote germination (Thomas et al. 2007, 2010; Mackenzie et al. 2016). Research on fire-stimulated germination of serotinous species has focussed largely on the release of seeds from fruits and cones by fire (Causley et al. 2016; Lamont et al. 2020). The possible effects of heat and smoke on germination of serotinous species have rarely been considered (Midgley and Viviers 1990; Dixon et al. 1995; Hanley and Lamont 2000; Ne'eman et al. 2009) even though serotinous seeds are exposed to a heat pulse during the passage of fire (Bradstock et al. 1994) and, once released, to water-soluble smoke chemicals adsorbed by soil particles and released following rainfall (Preston and Baldwin 1999).

The genus Leucadendron (Proteaceae) is an important component of fynbos with 85 species and numerous subspecies recognised (Williams 1972; Rebelo 2001). Alarmingly, 51 of these taxa are threatened with extinction with a further 13 taxa considered near threatened (SANBI 2017). The genus consists of dioecious evergreen shrubs that may be locally dominant or emergent in some communities (Cowling and Holmes 1992). Leucadendron arose about 30 million years ago (Sauquet et al. 2009) at a time when fire-adapted traits were beginning to diversify during the Cenozoic (Lamont and He 2017). Consistent with other Cape Proteaceae, many Leucadendron species (47\%) release their seeds at maturity while the remainder retain their seeds in cones. The degree of serotiny is relatively weak (typically 1-4 years' retention; Williams 1972; Bond 1985; Midgley and Enright 2000) compared with other fire-prone floras (e.g. southwestern Australia, where seed retention among Proteaceae can exceed 10 years; Enright et al. 1998). Hence, even among serotinous Leucadendron species, there may be substantial seed release in the absence of fire, and this is increasingly likely in older individuals (Mustart et al. 1994). Serotinous fruits are either flattened, winged achenes that are dispersed by wind, or rounded nutlets that drop to the ground following their release. Following their release after fire, serotinous seeds are blown or washed into litter microsites and become covered by soil, ash and charred plant remains to a mean depth of 5-15 mm (Bond 1985; Lamont et al. 1993, BBL personal observations). Non-serotinous fruits are always nutlets and these are usually collected from the soil surface and stored underground by ants, rodents and, possibly, dung beetles (Bond and Slingsby 1983; Midgley et al. 2002, 2015). Phylogenetic trait-assignment studies indicate that serotiny with winged achenes is the ancestral condition, followed by serotinous nutlets, with soil-stored nutlets the most derived condition (Lamont and He 2012). Leucadendron fruits are indehiscent, containing a single seed fused to the pericarp (Williams 1972), and are, hereafter, referred to as seeds.

Following release, seeds of most serotinous species are typically short-lived ( $<2$ years) and germinate readily in the first wet season (Williams 1972; Holmes and Newton 2004; Lamont et al. 2020). Serotinous cones are exposed briefly to the high temperatures of a fire that kills the plant or branch, with subsequent desiccation resulting in cone opening and seed release (Rebelo 2001). Simulation of this type of heat $\left(650{ }^{\circ} \mathrm{C}\right.$ for $90 \mathrm{~s}$, internal cone temperature reaching $\left.47^{\circ} \mathrm{C}\right)$ enhanced seed germination in three Leucadendron species ( $72 \%$ increase in L. conicum, $20 \%$ increase in L. eucalyptifolium and L. uliginosum) but decreased germination in one species (60\% decrease in L. salignum) compared with the non-heated controls. However, as the only resprouter here, L. salignum is not completely dependent on seeds for regeneration (Midgley and Viviers 1990). Aqueous smoke has been shown to enhance germination by $19-41 \%$ (compared with the non-smoked constant temperature controls) in four serotinous species ( $L$. coniferum, $L$. rubrum, $L$. salignum - Brown et al. 2003, and L. conicum - Brown and Botha 2004). These reports of enhanced germination are surprising given that seeds of serotinous species (where seed retention in the crown is $\geq 1$ year) are typically non-dormant after release (Baskin and Baskin 2014).

Early studies on germination of soil-stored Leucadendron seeds adopted an ad hoc physiological approach, examining water-soluble inhibitors (Brown and van Staden 1971; van Staden and Brown 1972), the effect of scarification, leaching, light, stratification, oxygen and applied hormones (Brown and van Staden 1973a, b; van Staden and Brown 1973; Brown and Dix 1985), and the effect of $\mathrm{H}_{2} \mathrm{O}_{2}$ (Brits 1986a). Subsequent studies switched to a more ecological approach, focussing on the direct effects of fire on germination. Nutlets of geosporous Leucadendron species possess a thick woody pericarp that protects the seed from predation (Rusch et al. 2013), microbial 
decay (Brown and van Staden 1973a, b; Lamont and Milberg 1997) and from the heat of a fire (Williams 1972) that can exceed $700{ }^{\circ} \mathrm{C}$ at the soil surface and $80{ }^{\circ} \mathrm{C}$ at a depth of $40 \mathrm{~mm}$ (Newton et al. 2006). Heat has received little attention as a germination cue in soil-stored Leucadendron, although Williams (1972) noted its positive effects on L. sessile (increase of $18-31 \%$ ) and L. tinctum (increase of 20-55\%). Aqueous smoke has been shown to enhance germination by $26-62 \%$ in two soil-stored species (L. arctuatum and L. tinctum; Brown and Botha 2004). Unlike species in the Fabaceae that exclude water entry via an impermeable seed coat, Leucadendron seeds do not appear to possess physical dormancy as usually understood (Baskin and Baskin 2014). However, positive effects of scarification and seed-coat removal, often used to break physical dormancy, have been demonstrated in $L$. tinctum (Brown and Dix 1985). This is consistent with the 'oxygen-impermeable physical dormancy' described for the closely related genus Leucospermum (Brits and Manning 2019) that is more widely accepted as physiological dormancy (as defined by Baskin and Baskin 2014), given that the seed coat is thick but water-permeable (thereby precluding physical dormancy). For the vast majority of nutlet-bearing Leucadendron species, however, germination requirements remain poorly understood even though such information is essential for their effective propagation and conservation management, especially of rare and threatened taxa.

Strong diurnal temperature fluctuations that occur in soil over summer or following vegetation removal by fire have received some attention as germination cues (Brits 1986b, 1987; Auld and Bradstock 1996; Moreira et al 2010; Santana et al. 2013). Brits (1986b) has studied the likely temperature fluctuations in pre- and post-burn surface soil in detail. This work showed for the hottest month of the year, at a soil depth of $5 \mathrm{~mm}$, that the warmest $12 \mathrm{~h}$ period of the day averaged $28{ }^{\circ} \mathrm{C}$ and coolest $12 \mathrm{~h}$ averaged $22{ }^{\circ} \mathrm{C}$ under heavy shade, $41{ }^{\circ} \mathrm{C}$ and $22{ }^{\circ} \mathrm{C}$ under light shade and $47{ }^{\circ} \mathrm{C}$ and $28{ }^{\circ} \mathrm{C}$ for mineral soil exposed after fire. There is evidence among some species of a minor increase in the level of germination when subjected to such conditions (Moreira et al. 2010) or even a decrease among others (Luna 2020). Increased alternating postfire temperatures can break physical dormancy to a limited extent (Ooi et al. 2012) or cause endotesta tearing in Leucospermum, facilitating increased oxygen supply to the embryo, thereby promoting germination (Brits et al. 1993). These dormancy-breaking effects need to be distinguished from incubation conditions for germination where low $\left(\leq 11^{\circ} \mathrm{C}\right.$; Yan et al. 2001) or cooler fluctuating temperatures, such as $20 / 10{ }^{\circ} \mathrm{C}$ (Brown and Botha 2004), promote germination. Such temperatures ensure germination occurs in late autumn/winter following substantial rain, thereby avoiding responding to unseasonal rainfall during the usual summer drought (Bond 1984; Mustart and Cowling 1993).

Leucadendron is the only genus in the world known to possess (a) species with either plant-stored or soil-stored seeds, and (b) plant-stored seeds that are either flat and winged or rounded nutlets, with equivalent soil-stored nutlets also well-represented in this genus (Rebelo 2001; Thuiller et al. 2004; Tonnabel et al. 2014). This provides a unique opportunity for comparative germination studies unfettered by the potential confounding effects of different phylogenetic and biogeographic histories on plant traits. Thus, this background shows that we have (i) unexpected increases in germination of some serotinous Leucadendron species following heat or smoke treatments, (ii) an opportunity to test germination requirements of geosporous species that, in general, are poorly known and (iii) great variation in seed morphology and seed bank types within a single genus.

Within this context, we investigated the individual and combined effects of heat and smoke on germination of 40 species comprising a mixture of life-history and functional traits, including 22 species for which no previously published germination data were available. We focused on simulating conditions that seeds would be exposed to under field conditions in the postfire environment and asked the following: (1) What are the individual and combined effects of heat and smoke on germination? (2) What types of germination syndromes can be identified? (3) How well do phylogeny and life-history traits such as persistence strategy, seed morphology and seed storage location correlate with these syndromes?

\section{Materials and methods}

\section{Species and seed source}

Seeds of 40 Leucadendron species collected from wild plants in the Western and Eastern Cape Provinces of South Africa between 2001 and 2014 were used in this study (Table S1; authorities, subspecies and varieties are provided here). Cones, no older than 4 years, were collected from a minimum of 40 individual plants, except $L$. flexuosum, $L$. meridianum, $L$. loranthifolium and $L$. foedum where 25,20 , 10 and two plants were sampled, respectively, due to small population size. The species were selected to represent all lineages within the genus based on Tonnabel et al. (2014) and as far as possible included a reasonable sample across the genus of contrasting seed bank types (canopy-stored, soil-stored), seed morphologies (nutlets, winged achenes) and persistence strategies (resprouter, non-resprouter) (Table S1). Limited seed collection opportunities (nutlets have to be collected when they are mature but before they are released) coupled with restricted availability of suitable 
collections already held at the MSB, resulted in under-representation of soil-stored nutlets. Seeds were sent to the Millennium Seed Bank at Wakehurst in West Sussex, England, and dried to equilibrium at $15 \% \mathrm{RH}$ and $18{ }^{\circ} \mathrm{C}$. Except for the four species collected in 2014 (the year of the experiments), dried seeds, collected between 2001 and 2008, were stored at international gene bank standards of $-20^{\circ} \mathrm{C}$, thus greatly reducing the risk of seed viability loss in these collections prior to their use.

\section{Imbibition tests}

A subset of 13 species ( $n=10$ seeds per species) including canopy- and soil-stored nutlets and winged seeds (Table S1) were tested for coat permeability by weighing seeds before and after immersion in water for $96 \mathrm{~h}$.

\section{Germination experiments}

\section{Experimental design}

A fully orthogonal design was used to test the individual and combined effects of direct fire cues (heat pulse and smoke) on postfire germination of 37 Leucadendron species (Experiment 1, Table S1). For three additional species, only the combined effect of heat pulse and smoke was examined due to limited seed availability (Experiment 2, Table S1). A postfire after-ripening treatment ( 8 weeks of dry storage at $12 \mathrm{~h} / 12 \mathrm{~h}$ alternating temperatures of $40 / 20{ }^{\circ} \mathrm{C}$ with $12 \mathrm{~h} / 12 \mathrm{~h}$ light/dark) was applied to all seeds in Experiments 1 and 2. This was intended to simulate postfire summer temperatures beneath the soil surface (Auld and Bradstock 1996), likely to be encountered following burial of serotinous seeds by soil and litter (Lamont et al. 1993) and burial of geosporous seeds by ants (Bond and Slingsby 1983) or rodents (Midgley et al. 2002). Seeds in the control treatment received only the postfire after-ripening treatment. Seeds in the heat-only treatment and the combined heat plus smoke treatment received a heat treatment (described below) prior to the postfire after-ripening treatment. Seeds in the smokeonly treatment and the combined heat plus smoke treatment, received a smoke treatment (described below) after the postfire after-ripening treatment, consistent with the release of smoke chemicals adsorbed by soil particles at the onset of the wet season (Preston and Baldwin 1999). Five replicates of 50 seeds were used in each treatment except for eight species in which five replicates of 25 seeds were used (Table S1). For each species, each replicate was set up independently of the others and at weekly intervals, such that the first replicate was placed in incubators in week 1 and the fifth and last replicate was placed in incubators 5 weeks later.

\section{Heat pulse treatment}

Replicate batches of seeds requiring the heat pulse treatment were independently, and at weekly intervals over a period of five weeks, heated to $80^{\circ} \mathrm{C}$ for $20 \mathrm{~min}$ inside a temperaturecontrolled incubator. This treatment was chosen to simulate the heat pulse from a heathland fire passing over seeds up to a depth of $40 \mathrm{~mm}$ (Newton et al. 2006), after considering results in Keeley and Bond (1997) and Hanley and Lamont (2000), and to avoid potentially lethal temperatures (Moreira et al. 2010). The temperature within the incubator was monitored with a thermocouple thermometer to ensure it remained within $2{ }^{\circ} \mathrm{C}$ of the set temperature. Following treatment, seeds were equilibrated to ambient temperature in the laboratory before being subjected to the postfire afterripening treatments described above.

\section{Smoke treatment}

Regen2000® Smokemaster liquid smoke solution (Batch number 11468, Grayson, Australia) was filtered through a sterile $0.2 \mu \mathrm{m}$ Nalgene cellulose acetate $\times 50$ filter syringe (Fisher Scientific, Loughborough, UK) to exclude microbes and particulates prior to dilution with distilled water (1:10, as per manufacturer instructions) for smoke treatments. At the end of the postfire after-ripening treatment, replicate batches of seeds were placed in separate individual Coulter ${ }^{\circledR}$ Counter containers and completely immersed in at least $10 \mathrm{~mL}$ (or up to a maximum of $20 \mathrm{~mL}$ for larger seeds) of dilute smoke solution (for seeds receiving smoke) or distilled water (controls). The containers were sealed and incubated at $20^{\circ} \mathrm{C}$ for $24 \mathrm{~h}$, after which seeds were removed and blotted dry. The replicates for each species were prepared independently of the others and at weekly intervals, and fresh smoke solution was prepared each week.

\section{Germination tests}

Following the above pre-treatments, seeds were sown on $1 \%$ distilled water agar in $90 \mathrm{~mm}$ Petri dishes (except for large-seeded $L$. argenteum, $L$. loranthifolium and $L$. tinctum that were sown in square polyethylene containers measuring $100 \times 100 \times 20 \mathrm{~mm}$ ). These were then placed in temperaturecontrolled incubators at $20 / 10{ }^{\circ} \mathrm{C}(12 \mathrm{~h}$ light/12 h dark $)$ to simulate near-surface soil autumn-winter temperatures in post-fire fynbos known to promote germination (Brits 1986b, 1987; Brown and Botha 2004). Germination was assessed at regular intervals (initially daily and then twice weekly or weekly). Seeds were scored as germinated and removed once the radicle was longer than $2 \mathrm{~mm}$. Seeds visibly deteriorated because of fungal contamination were assumed to be nonviable and were removed, while the remaining seeds were placed on fresh agar to prevent fungal spread. Germination 
tests were terminated once there was no germination in any replicate for at least 4 weeks and any remaining seeds were dissected to assess seed fill and viability. Firm seeds containing an embryo were considered viable while seeds that had deteriorated during the germination test were considered non-viable. Germination was calculated relative to viable seeds sown to ensure poor germination was due to a lack of germination response rather than variable seed viability.

\section{Data analyses}

Germination data were analysed using Bayesian inference given a number of key advantages over classical frequentist inference involving Null Hypothesis Significance Testing (NHST). These include the following: (i) richer and more informative inferences through the provision of complete distributional information for all model parameters and related functions via the posterior distribution; (ii) reliance on the data actually observed instead of $p$-values and confidence intervals based on hypothetical unobserved data; (iii) the ability to accept, as well as reject, null values; (iv) the ease with which functions of model parameters (including treatment differences) and their uncertainty can be quantified exactly; and (v) the insensitivity of the posterior distribution to intended or post hoc comparisons (Kruschke et al. 2012). Furthermore, Bayesian inference provides a practical solution to the problem of separation (perfect prediction of a binary response variable by one or more predictors, as in $0 \%$ or $100 \%$ germination in one or more experimental treatments) often encountered in logistic regressions.

The number of seeds germinated $\left(G_{i}\right)$ out of the number of viable seeds $\left(V_{i}\right)$ in each Petri dish $(i)$ was assumed to follow a binomial distribution with probability $\pi_{i}$, and was analysed using generalised linear models (GLMs) with a logistic link function, as follows:

$$
G_{i} \sim \operatorname{Binomial}\left(\pi_{i}, V_{i}\right)
$$

$\operatorname{logit}\left(\pi_{i}\right)=\eta_{i}$

(i) $\eta_{i}=\beta_{0}+\beta_{1} \times H_{i}+\beta_{2} \times S_{i}+\beta_{3} \times H_{i}$

$\times S_{i}$ (Experiment 1$)$, or

(ii) $\eta_{i}=\beta_{0}+\beta_{1} \times H S_{i}$ (Experiment 2)

where $\eta$ is the logit proportion of viable seeds that germinated, $H$ is the effect of heat, $S$ is the effect of smoke, $H \times S$ is the interaction between heat and smoke, $H S$ is the effect of the combined heat plus smoke treatment, and $\beta_{0}-\beta_{3}$ are regression coefficients with $\beta_{0}$ (the intercept) corresponding to the control treatment in each experiment. The proportion of viable seeds germinated, $\pi_{i}$, is given by $e^{\eta_{i}} /\left(1+e^{\eta_{i}}\right)$.
Model parameters were estimated using Bayesian Markov Chain Monte Carlo (MCMC) methods with uninformative priors. Analyses were conducted using the free software R (version 3.5.2, R Core Team 2018) and JAGS (Plummer 2013) via the package 'R2jags' (Su and Yajima 2015). Five chains, each comprising 80,000 iterations, were used in the MCMC process with a burn-in of 50,000 iterations and a thinning rate of 10 , giving a combined total of 15,000 samples for each posterior distribution. Models were considered to have converged when traceplots were well mixed and the Gelman-Rubin statistics were below 1.1. Estimated sample sizes $($ ESS $)>10,000$ for all regression parameters and derivative functions ensured chain stability and accuracy. Model adequacy was assessed using graphical posterior predictive checks and Bayesian $p$-values (Gelman et al. 1996).

Poor chain convergence and/or strong autocorrelation were addressed by increasing the number of iterations, the thinning rate, and, in some cases, using weakly informative priors (Table S2). Complete separation was addressed using weakly informative Student's $t$ priors (Ghosh et al. 2018; Table S2). Overdispersion (greater variability in the data than is consistent with a binomial model) was addressed using generalised linear mixed models (GLMMs) and the addition of an observation-level random effect for Petri dish, $\varepsilon_{i} \sim N\left(0, \sigma_{i}^{2}\right)$, to the GLMs described above. Further details regarding the final model parameters are provided in Tables S3 and S4.

All model parameters and related functions, including germination probabilities, treatment effects (absolute differences in $\%$ germination between treatments) and interaction effects (the absolute effect of the interaction term on $\%$ germination in Experiment 1) were estimated from the posterior distribution. Modal values were taken as the best estimates and uncertainty was described using 95\% Highest-Density Intervals (HDI, the $95 \%$ most credible/highest probability density parameter values). Our primary interest was in the magnitude of the differences in $\%$ germination between the fire-related treatments and the control. When the HDI of a parameter excludes a target value, that value can be rejected as credible (analogous but not equivalent to a 'statistically significant difference' in frequentist NHST). However, this does not imply any substantive or biological significance (e.g. Lecoutre et al. 2001; Schwab et al. 2011; Wasserstein et al. 2019). We treated an absolute difference in germination probability between treatments of $10 \%$ as the minimum effect size of biological interest. Similarly, when assessing the relative contributions of heat and smoke to the maximum germination response, we interpreted control germination $\geq 50 \%$ as evidence against an obligate requirement for direct fire cues. Adapting the HDI + ROPE (Region of Practical Equivalence) decision rule (Kruschke 2018), treatment effects with 95\% HDIs completely contained within the interval [-10\%-10\%] (the ROPE) were classified 

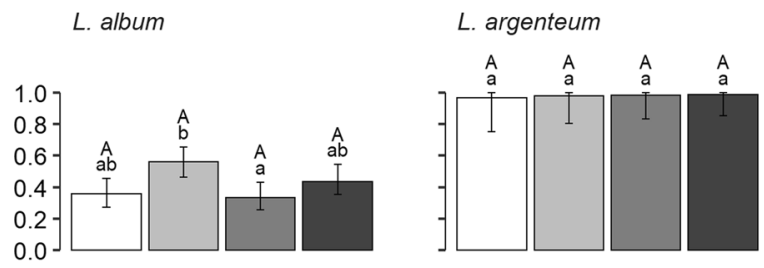

L. brunioides

L. chamalaea

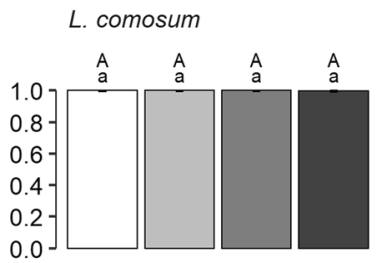

L. coniferum
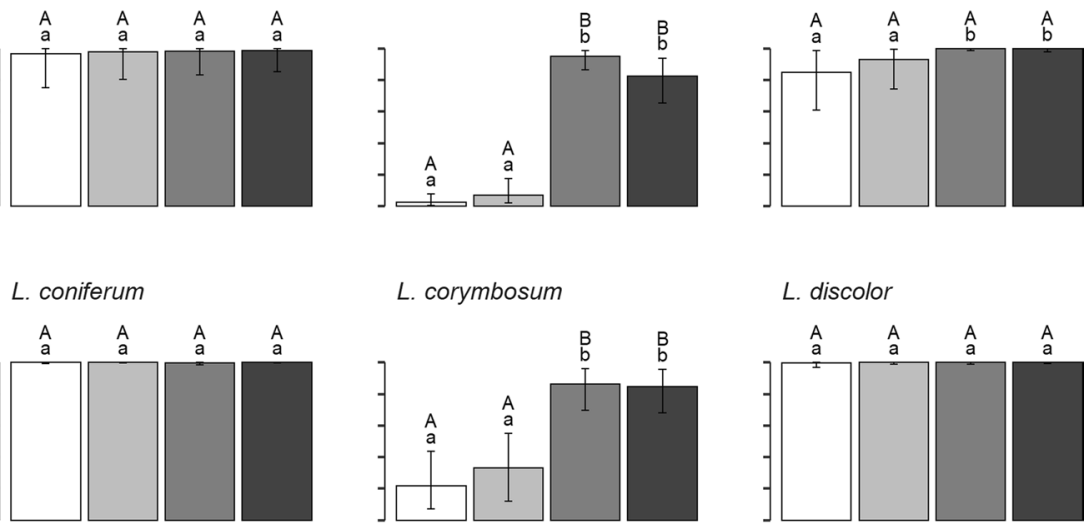

L. corymbosum

L. discolor
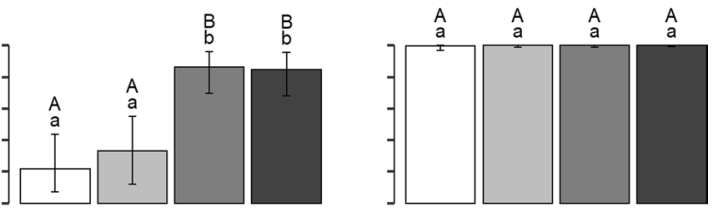

L. dregei

L. elimense

L. galpinii

L. laxum
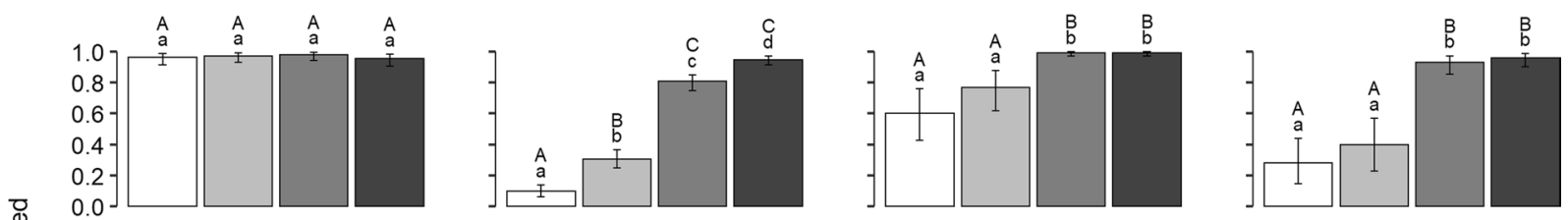

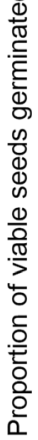

L. linifolium

L. Ioranthifolium

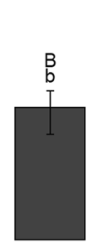

L. microcephalum

L. modestum
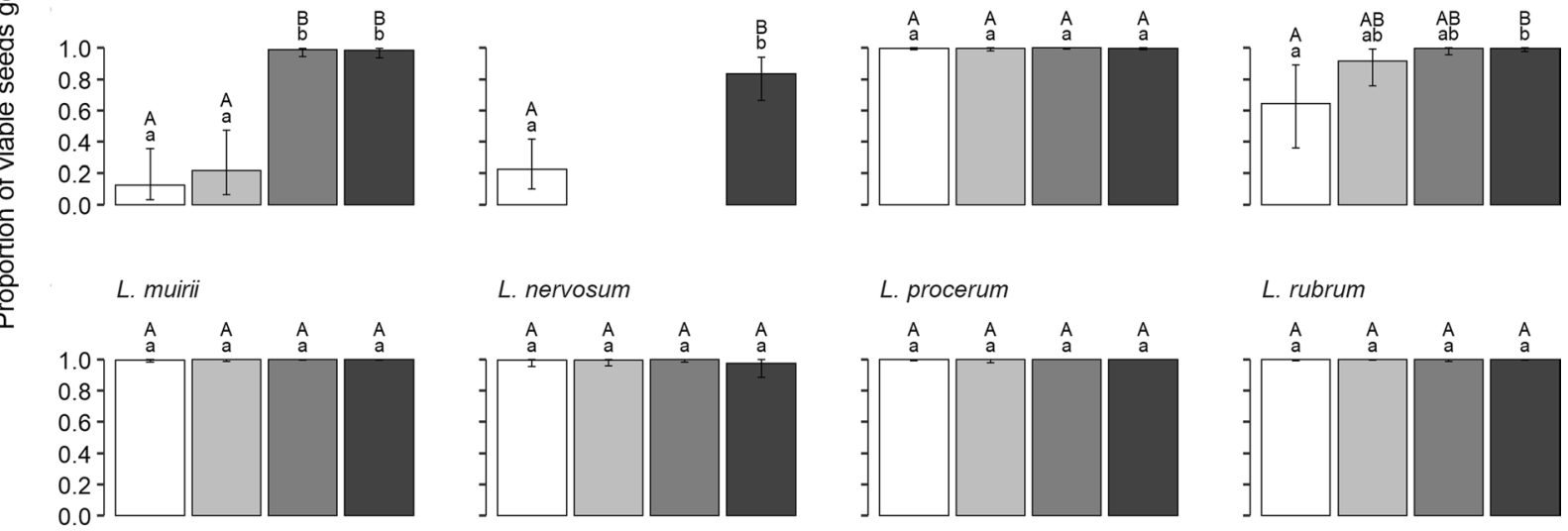

L. nervosum

L. procerum

L. rubrum
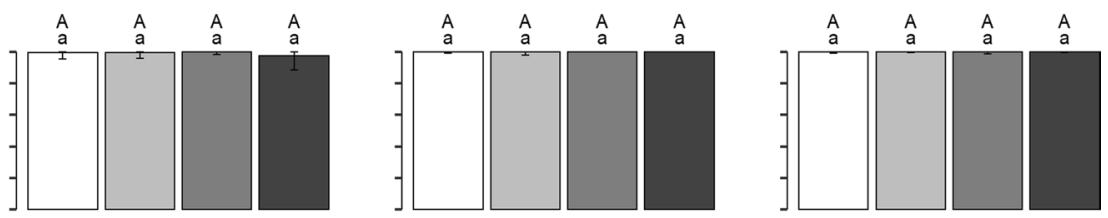

L. salicifolium

L. sericeum

L. spissifolium

L. stelligerum
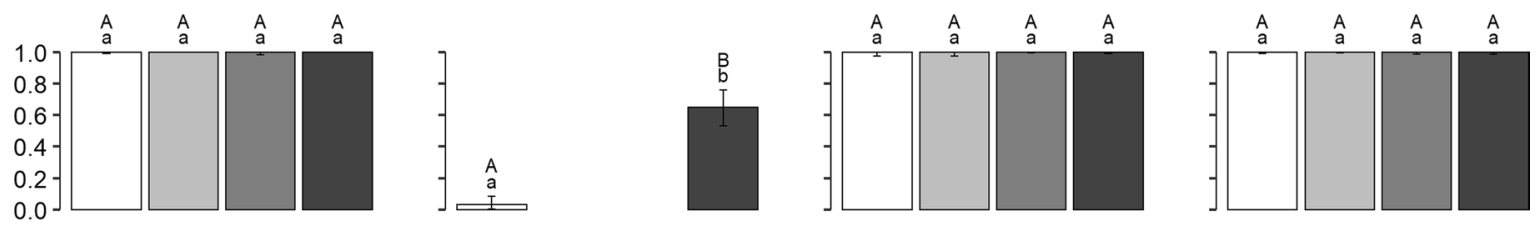

C $\mathrm{H} \quad \mathrm{S}$ HS

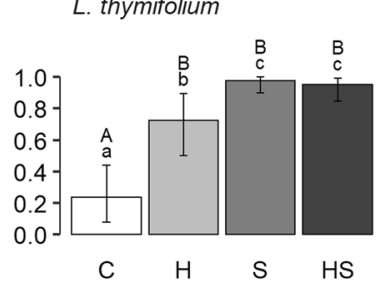

L. tinctum

L. uliginosum
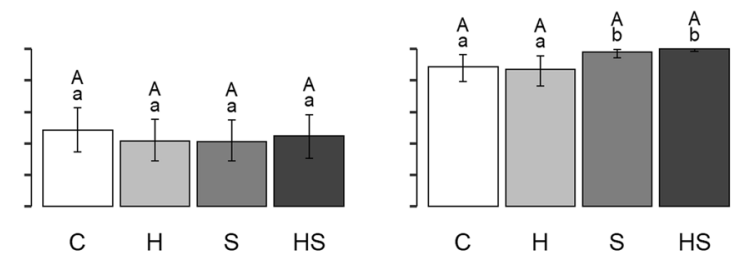

Treatment 
4Fig. 1 Germination of 27 species of Leucadendron (Proteaceae) in response to fire-related germination cues. Treatments are as follows: control (C), heat $(\mathrm{H})$, smoke (S) and heat plus smoke (HS). Data are modal germination \pm Bayesian 95\% Highest-Density Intervals (quantitative data are provided in Table S5). Different lowercase letters above bars indicate credible non-zero differences between means. Different uppercase letters indicate 'biologically non-trivial' differences. Identical uppercase letters indicate either: (i) 'biologically trivial' differences, or (ii) insufficient evidence to distinguish biologically trivial from non-trivial effects (see Materials and Methods; Table S7). Individual heat and smoke treatments were not applied to L. loranthifolium or L. sericeum. The 13 species that germinated to $100 \%$ across all experiment treatments have been omitted

as follows: 'biologically trivial' (negligibly different from/ practically equivalent to zero); those falling completely outside the ROPE as 'biologically non-trivial' (non-negligibly different from zero); and those overlapping the ROPE as 'uncertain'. Control germination was interpreted in a similar manner using a ROPE of $[0 \%, 50 \%]$.

Contingency tables directed at summarising the relationships between fire-stimulated germination and life-history and seed traits were analysed using Bayesian proportional tests via the R package 'BayesianFirstAid' (Bååth 2014). To confirm phylogenetic independence of the species sampled, phylogenetic signal among biologically significant germination response to smoke or heat was quantified using Bloomberg's K and significance tests, based on the Leucadendron molecular phylogeny of Tonnabel et al. (2014). Species that were tested for germination response, but not included in the Leucadendron phylogeny, were surrogated by ecologically similar species (i.e., $L$. nobile was surrogated by $L$. osbornei, $L$. coniferum by L. meridianum and $L$. tinctum by L. barkerae). Analysis of phylogenetic signal was conducted using the R package 'phytools' (Revell 2012).

Data of the form $\mathrm{X} \%$ (Y\%, Z\%) reported hereafter in the main text and tables are modal values plus 95\% HDIs.

\section{Results}

Thirteen serotinous species with winged achenes ( $L$. eucalyptifolium, L. flexuosum, L. foedum, L. gandogeri, L. lanigerum, L. laureolum, L. meridianum, L. nobile, L. rourkei, $L$. salignum, L. strobilinum, $L$. teretifolium and $L$. xanthoconus) germinated to $100 \%$ in every treatment and were, therefore, not subjected to statistical analysis. Of the remaining 27 species, modal germination in the control treatment (summer postfire dry after-ripening treatment of $40 / 20{ }^{\circ} \mathrm{C}$ followed by moist incubation at autumn-winter postfire temperatures of $20 / 10{ }^{\circ} \mathrm{C}$ ) exceeded $50 \%$ for 17 species but was less than $20 \%$ for four species (L. brunioides, L elimense, L. linifolium and $L$. sericeum). Modal germination of all species reached $80-100 \%$ in at least one treatment except for $L$. album, $L$. sericeum and L. tinctum (Fig. 1, Table S5). Average seed mass for 13 species (Table S1) increased by $>20 \%$ (based on air-dried seed mass) for all species tested, indicating that seeds of all of these species are permeable to water, based on criteria in Baskin and Baskin (2003).

\section{Germination syndromes}

Several broad germination syndromes were evident in the data (Fig. 2, Table S5, S6): (i) taxa with fire cue-dependent germination $(n=8)$, where a heat pulse and/or smoke was required for $\geq 50 \%$ germination (mean control germination $2-28 \%$ ); (ii) taxa with fire cue-enhanced germination $(n=2)$, where smoke had a non-trivial promotive effect but germination was $85-88 \%$ likely to be $\geq 50 \%$ (mean $60-65 \%$ ) in its absence (the alternative, fire cue-dependent germination, was only $12-15 \%$ likely); (iii) taxa with fire cue-independent germination $(n=24)$, where both heat pulse and smoke had trivial effects and mean control germination was $96-100 \%$; and (iv) taxa with uncertain germination responses to fire $(n=6)$, where there was insufficient evidence to distinguish biologically trivial from non-trivial promotive effects of heat and/or smoke; however, germination was not fire cue-dependent with a mean control germination of 85-99\% (apart from L. album and L. tinctum that germinated poorly overall). The fire-dependent group is almost entirely geosporous with a single serotinous member (L. linifolium). Both the fire-enhanced and fire-independent groups comprise serotinous taxa only, while the uncertain group is a mixture of seed bank types.

\section{Heat pulse responses}

Heat had a non-trivial effect on two geosporous species, L. elimense and $L$. thymifolium, improving germination by $21 \%(14 \%, 28 \%)$ and $47 \%(18 \%, 73 \%)$, respectively (Fig. 2, Tables S6, S7). The effect of heat was trivial on a further 24 species, all of which were serotinous, but was uncertain for the remaining 11 species. Among the latter, heat had a potentially minor effect on L. album [20\% (6\%, 33\%), 94.9\% of HDI outside ROPE].

\section{Smoke responses}

Smoke had a positive, non-trivial effect on seven species [including two serotinous species, improving germination by $39 \%(23 \%, 56 \%)$ to $91 \%(82 \%, 97 \%)$ (Fig. 2, Tables S6, S7)]. The effect of smoke was trivial on a further 24 species but was uncertain on the remainder, although its effect on L. modestum was likely non-trivial [34\% (9\%, 62\%), 99.6\% of HDI outside ROPE]. 
Fig. 2 Generalised effects of fire-related cues on germination of 40 Leucadendron species arranged by germination, seed trait and regeneration syndromes. Germination syndromes (GS): FD (fire cue-dependent) one or more direct fire (smoke/heat) cues are required for $\geq 50 \%$ germination; FE (fire cue-enhanced) one or more direct fire cues have a non-trivial $(\geq 10 \%)$ promotive effect but germination is ( $\geq 85 \%$ ) likely to be $\geq 50 \%$ in their absence; FI (fire cueindependent) direct fire cues have trivial $(<10 \%)$ effects on germination and germination is $\geq 50 \%$ in their absence; and FU (fire cue effects uncertain) insufficient evidence to distinguish trivial from non-trivial fire effects; however (with the exception of $L$. album and $L$. tinctum that had low overall germination), direct fire cues are not required for substantial ( $\geq 50 \%$ ) germination. Seed trait syndromes: $S B$ seed bank type ( $C$ canopy-stored, $S$ soilstored); $S M$ seed morphology ( $N$ nutlets, $W$ winged achenes) $P S$ persistence strategy (NR non-resprouter, $R$ resprouter). Germination cues: $C$ control; $H$ heat; $S$ smoke; $H S$ heat + smoke; $N T$ biologically non-trivial response; $\mathrm{T}$-biologically trivial response; ? Uncertain response; blank-treatment not applied. Shading indicates the proportion of the 95\% HDI inside the ROPEs for control germination and treatment effects, respectively, except for 13 species (*) where the probabilities of trivial control germination and trivial treatment effects are inferred to be 0 and 1 , respectively, on the basis of $100 \%$ germination in all treatments. Refer to Materials and Methods for details, and to Table S7 for quantitative data on effect sizes. Life-history and seed trait data obtained from Williams (1972), Rebelo (2001) and Tonnabel et al. (2018)
SB SM PS C H S HS

L. linifolium
L. elimense
L. sericeum
L. corymbosum
L. laxum

L. Ioranthifolium

L. thymifolium

L. brunioides

L. galpinii

L. modestum FE

C N N NR $\mathrm{T}$ ?

\begin{tabular}{lllll|l|l}
$S$ & $N$ & $N R$ & $T$ & $N T$ & $N T$ & $N T$
\end{tabular}

$S \quad N \quad N R T$

S N NR T ? NT NT

$S \quad N \quad N R T$ T

\begin{tabular}{lll|l|l|l|l}
$S$ & $N$ & $N R$ & $T$ & $N T$ & $N T$ & $N T$
\end{tabular}

$\begin{array}{llllllll}S & N & R & T & ? & N T & N T\end{array}$

L. album

L. argenteum

L. nervosum

L. uliginosum

L. chamalaea

L. tinctum

L. dregei

L. rubrum

*L. rourkei

*L. lanigerum

L. comosum

L. coniferum

L. discolor

${ }^{*}$ L. eucalyptifolium

*L. foedum

${ }^{*}$ L. gandogeri

*L. laureolum

*L. meridianum

L. microcephalum

L. muirii

${ }^{*}$ L. nobile

L. procerum

L. salicifolium

L. stelligerum

*L. strobilinum

*L. teretifolium

${ }^{*}$ L. xanthoconus

*L. flexuosum

*L. salignum

L. spissifolium
FU

C N NR ? ?

C W NR ? ? ? NT

C N NR T ? ? ?

C N NR NT ? ? ?

\begin{tabular}{lllll|l|l}
$C$ & $N$ & $N R$ & $N T$ & $T$ & $T$ & $?$
\end{tabular}

C W NR NT ? ? ?

S N NR NT ? ?

$\mathrm{S} N \mathrm{NR}$

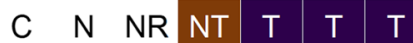

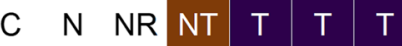

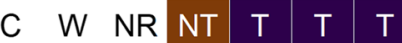

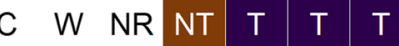

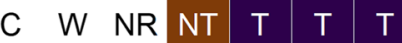

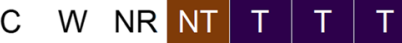

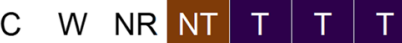

$\begin{array}{lllllll}C & W & N R & N T & T & T & T\end{array}$

C W NR

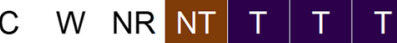

$\begin{array}{lllllll}\text { C } & \text { W } & \text { NR } & \text { NT } & \text { T } & \text { T } & \text { T }\end{array}$

$\begin{array}{lllllll}C & W & N R & N T & T & T & T\end{array}$

FI

$\begin{array}{lllllll}\text { C } & \text { W } & \text { NR } & \text { NT } & \text { T } & \text { T } & \text { T }\end{array}$

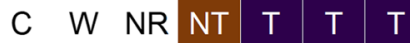

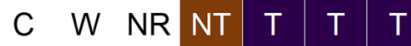

\begin{tabular}{llllll|l}
$C$ & $W$ & NR & NT & T & T & T
\end{tabular}

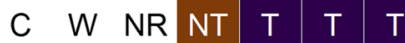

\begin{tabular}{llllll|l}
$C$ & W & NR & NT & T & T & T
\end{tabular}

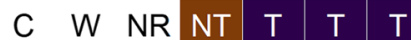

$\begin{array}{lllllll}C & \text { W } & \text { NR } & \text { NT } & \text { T } & \text { T } & \text { T }\end{array}$

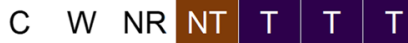

C W R NT

\begin{tabular}{lllll|l|l}
$C$ & $W$ & $R$ & $N T$ & $T$ & $T$ & $T$
\end{tabular}

\begin{tabular}{lllll|l|l}
$C$ & $W$ & $R$ & $N T$ & $T$ & $T$ & $T$
\end{tabular}
Proportion of HDI inside ROPE

$90<\mathrm{P} \leq 100$

$80<\mathrm{P} \leq 90$

$70<\mathrm{P} \leq 80$

$60<P \leq 70$

$50<P \leq 60$

$40<P \leq 50$

$30<\mathrm{P} \leq 40$

$20<\mathrm{P} \leq 30$

$10<P \leq 20$

$0 \leq P \leq 10$ 


\section{Responses to combined heat plus smoke}

The combined heat plus smoke treatment had a positive, non-trivial effect on the same seven species as the smokeonly treatment plus an additional three species, two of which did not receive a smoke-only treatment. Trivial effects were observed for 24 other species with the effect on an additional species, $L$. nervosum, also likely to be trivial [ $-1 \%$ $(-12 \%, 4 \%), 98.4 \%$ of HDI inside ROPE]. The effect of the combined heat plus smoke treatment was uncertain for the remaining species.

The difference in germination between the combined heat plus smoke treatment and the smoke-only treatment was trivial for 28 out of 37 species where both treatments were applied (including 13 species with $100 \%$ germination in both treatments; Fig. 2, Tables S6, S7) and uncertain in the remaining 9 species. Minor negative interactions between heat and smoke were observed for $L$. brunioides and L. thymifolium (Fig. 1, Table S3). Both interactions had an uncertain effect on germination [L. brunioides, $-15 \%$ (-34\%, - 2\%); L. thymifolium, - 4\% (- 15\%, 0\%); Table S7].

\section{Effects of phylogeny, life-history and seed traits}

Non-trivial germination responses to heat pulses and smoke were independent of species phylogenetic relationships ( $K=0.233, P=0.266 ; K=0.295, P=0.075$, respectively). Germination responses to fire cues (including both promotive effects and absolute requirements) were $80-90 \%$ more likely in species with soil seed banks than those with canopy seed banks (Table 1). There was little evidence of a difference in the frequency of fire-stimulated germination between resprouters and non-resprouters. Smoke-responsive species were $90 \%$ more likely to respond to heat than non-smokeresponsive species. Fire cues were $72 \%$ more likely to promote germination in nutlets than winged seeds. The prevalence of fire effects in nutlet-bearing species was $42 \%$ higher in those with soil seed banks versus canopy seed banks, and fire effects in serotinous species were $45 \%$ more common in those with nutlets than those with winged seeds (Table 1).

\section{Discussion}

The most important predictor of germination syndromes in Leucadendron is seed storage location (serotinous vs geosporous) followed by seed morphology (winged achenes vs nutlets). Excluding four serotinous species with uncertain germination responses in relation to fire cues, 96\% (22) of the serotinous, wing-seeded species examined exhibited fire-independent germination and 50\% (two) of serotinous, nutlet-bearing species displayed fire-enhanced germination
(Table 1). This contrasts with $100 \%$ (seven) geosporous, nutlet-bearing species with fire-dependent germination (Table 1). In terms of a possible evolutionary sequence, these traits and the associated germination syndromes reflect increased 'fine-tuning' to fire. Fire plays an indirect role in recruitment of species with serotinous, winged fruits (the ancestral condition in Leucadendron; Lamont and $\mathrm{He} 2012$; Tonnabel et al. 2018) by timing en masse seed release to the immediate postfire environment, although their relatively weak serotiny implies progressive seed release in the absence of fire, but does not manifest as recruitment, with these seeds lost to the seed bank [with the exception of $L$. argenteum, which maintains both serotinous aerial seedbanks and extremely long-lived soil-stored seed banks (Heelemann et al. 2013)]. Recruitment of geosporous species, on the other hand, is tightly coupled to fire, with smoke and (to a lesser extent) heat providing essential germination cues.

\section{Germination of serotinous species}

Serotinous species are widely regarded as non-dormant (Lamont and Enright 2000). However, our study provides evidence that direct fire cues promote germination in a few taxa. Most notably, we identified a serotinous species, $L$. linifolium, with an obligate smoke requirement for germination (Figs. 1, 2, Table S6). To our knowledge, this is only the third report of such a species in the literature and is the first report for the South African flora. However, this is contradicted by Yan et al. (2001), who obtained $71 \%$ germination under a $20 / 10{ }^{\circ} \mathrm{C}$ cycle of $16 \mathrm{~h} \mathrm{light} / 8 \mathrm{~h}$ dark, without any additional cues. Even so, the strong smoke response by $L$. linifolium in our collection is consistent with its membership of the nutlet clade I of Tonnabel et al. (2018) that contains five of the nine species in our fire-dependent/enhanced syndromes (Fig. 2) that respond to smoke. The other two serotinous obligate smoke species occur in southwestern Australia: Callitris (Actinostrobus) acuminata (Cupressaceae) requires smoke to germinate (Dixon et al. 1995) and Conospermum capitatum (Proteaceae) requires smoke or heat (Zhao and Ladd 2014). The designation of L. conicum as a fourth serotinous species with an obligate requirement for a fire cue (heat) seems reasonable on the basis of Midgley and Viviers (1990), where mean germination increased from $18 \%$ in the control to $90 \%$ with heat treatment although this is contradicted by Bond (1984), who reported $100 \%$ seed germination using untreated seeds of the same species.

Facultative smoke responses were displayed by two other serotinous species, L. galpinii [39\% $(23 \%, 56 \%)$ increase relative to control] and L. modestum [34\% (9\%, 62\%) increase] (Fig. 1, Table S7). Similar germination enhancements with smoke treatment were reported by Brown et al. (2003) for $L$. coniferum, $L$. rubrum and $L$. salignum, but these were 
Table 1 Summary of germination responses to fire cues in relation to seed bank and seed morphology

\begin{tabular}{|c|c|c|}
\hline & Soil & Canopy \\
\hline \multicolumn{3}{|l|}{ Fire effects vs seed storage location } \\
\hline Fire effect & 7 & 3 \\
\hline No fire effect & 0 & 24 \\
\hline Relative frequency of fire effects & $0.978[0.69,>0.999]$ & $0.106[0.033,0.264]$ \\
\hline \multicolumn{3}{|c|}{ Difference in prevalence of fire effects between groups: $0.810[0.514,0.943]$} \\
\hline \multicolumn{3}{|c|}{ Probability of greater prevalence of fire effects in species with soil seed banks: $>0.999$} \\
\hline & Soil & Canopy \\
\hline \multicolumn{3}{|l|}{ Heat effects vs seed storage location } \\
\hline Heat effect & 2 & 0 \\
\hline No heat effect & 0 & 24 \\
\hline Relative frequency of heat effects & $0.947[0.356,>0.999]$ & $0.007[<0.001,0.116]$ \\
\hline
\end{tabular}

Difference in prevalence of heat effects between groups: 0.896 [0.316, 0.995]

Probability of greater prevalence of heat effects in species with soil seed banks: $>0.999$

\begin{tabular}{lll}
\hline & Soil & Canopy \\
\hline Smoke effects vs seed storage location & & \\
Smoke effect & 5 & 2 \\
No smoke effect & 0 & 24 \\
Relative frequency of smoke effects & $0.971[0.599,>0.999]$ & $0.074[0.012,0.216]$
\end{tabular}

Difference in prevalence of smoke effects between groups: 0.829 [0.469, 0.962]

Probability of greater prevalence of smoke effects in species with soil seed banks: $>0.999$

\begin{tabular}{|c|c|c|}
\hline & Non-resprouter & Resprouter \\
\hline \multicolumn{3}{|l|}{ Fire effects vs persistence strategy } \\
\hline Fire effect & 9 & 1 \\
\hline No fire effect & 21 & 3 \\
\hline Relative frequency of fire effects & $0.293[0.158,0.472]$ & $0.234[0.027,0.669]$ \\
\hline \multicolumn{3}{|c|}{ Difference in prevalence of fire effects between groups: $0.029[-0.407,0.338]$} \\
\hline \multicolumn{3}{|c|}{ Probability of greater prevalence of fire effects in non-resprouters: 0.489} \\
\hline & Smoke effect & No smoke effect \\
\hline \multicolumn{3}{|l|}{ Heat effects vs smoke effects } \\
\hline Heat effect & 2 & 0 \\
\hline No heat effect & 0 & 24 \\
\hline Relative frequency of heat effects & $0.947[0.356,>0.999]$ & $0.007[<0.001,0.116]$ \\
\hline \multicolumn{3}{|c|}{ Difference in prevalence of heat effects between groups: $0.896[0.316,0.995]$} \\
\hline \multicolumn{3}{|c|}{ Probability of greater prevalence of heat effects in species with smoke effects: $>0.999$} \\
\hline & Nutlet & Winged \\
\hline \multicolumn{3}{|c|}{$\begin{array}{l}\text { Fire effects vs seed morphology (serotinous and geosporous species } \\
\text { combined) }\end{array}$} \\
\hline Fire effect & 9 & 1 \\
\hline No fire effect & 2 & 22 \\
\hline Relative frequency of fire effects & $0.813[0.54,0.961]$ & $0.049[0.003,0.185]$ \\
\hline \multicolumn{3}{|c|}{ Difference in prevalence of fire effects between groups: $0.721[0.442,0.91]$} \\
\hline \multicolumn{3}{|c|}{ Probability of greater prevalence of fire effects in species with nutlets: $>0.999$} \\
\hline & Soil & Canopy \\
\hline \multicolumn{3}{|c|}{ Fire effects vs seed storage location (nutlet-bearing species only) } \\
\hline Fire effect & 7 & 2 \\
\hline No fire effect & 0 & 2 \\
\hline
\end{tabular}


Table 1 (continued)

\begin{tabular}{lcc}
\hline & Soil & Canopy \\
\hline Relative frequency of fire effects & $0.976[0.683,>0.999]$ & $0.52[0.152,0.859]$ \\
Difference in prevalence of fire effects between groups: $0.417[-0.018,0.794]$ & \\
Probability of greater prevalence of fire effects in species with soil seed banks: 0.964 &
\end{tabular}

Probability of greater prevalence of fire effects in species with soil seed banks: 0.964

\begin{tabular}{lll}
\hline & Nutlet & Winged \\
\hline Fire effects vs seed morphology (serotinous species only) & & \\
Fire effect & 2 & 1 \\
No fire effect & 2 & 22 \\
Relative frequency of fire effects & $0.496[0.151,0.859]$ & $0.049[0.002,0.187]$
\end{tabular}

Difference in prevalence of fire effects between groups: 0.448 [0.045, 0.787]

Probability of greater prevalence of fire effects in species with nutlets: 0.990

Fire effect refers to a heat and/or smoke effect, and these include both fire cue-enhanced and fire cue-dependent germination responses. Group counts refer to non-trivial and trivial effects of heat and/or smoke only (uncertain effects have been excluded; refer to Table S7 and main text for details). Group frequencies and differences are mode plus Bayesian 95\% Highest-Density Intervals (the most credible parameter values). Note that non-trivial germination responses to heat and/or smoke were independent of species phylogenetic relationships

not supported in our study, with near-full germination of all three species by the control. Reports of mild (c. 20\%) improvements in mean germination with smoke treatment of other serotinous Proteaceae include Protea compacta (Brown 1993), Aulax cancellata (Brown et al. 2003) and L. conicum (Brown and Botha 2004). In contrast, Yearsley et al. (2018) observed no effect of smoke on germination of eight serotinous species of Western Australian Proteaceae.

There was no evidence of positive or negative effects of heat on germination of any of the 31 serotinous species examined in our study, including three species for which a positive effect (L. eucalyptifolium and L. uliginosum, Midgley and Viviers 1990; L. tinctum, Williams 1972) and one for which a $60 \%$ decrease in germination $(L$. salignum, Midgley and Viviers 1990) were reported previously. Promotive effects (Brown and Whelan 1998; Hanley and Lamont 2000) and nil or strong negative effects (Bell and Williams 1998; Ne'eman et al. 2009) of heat have also been reported for several other serotinous taxa. Reduced responses in these studies were attributed to seed death, though a heat pulse can suppress germination without affecting viability in some species (Collette and Ooi 2017; Luna 2020).

The heat treatment applied in our study $\left(80{ }^{\circ} \mathrm{C}\right.$ for $20 \mathrm{~min}$ ) did not reduce germination in any of the species tested so cannot be considered excessive. Heat tolerance is an essential prerequisite for soil-stored seeds, but it is noteworthy that such tolerance was also evident among all species with plant-stored seeds. This should facilitate survival of seeds stored in cones during the passage of fire when raised temperatures can occur despite insulation by the woody scales (e.g. over $60{ }^{\circ} \mathrm{C}$ for up to $15 \mathrm{~min}$ inside woody follicles of Hakea dactyloides; Bradstock et al. 1994) and of seeds of weakly serotinous Leucadendron species that may be released and incorporated into the soil prefire.
Survival of seeds without affecting germination following similar heat treatments has been noted among serotinous species in a number of sclerophyll genera (Bradstock et al. 1994; Hanley and Lamont 2000; Hall et al. 2017) as well as non-serotinous species in other regions (Williams et al. 2003; Gómez-González et al. 2017).

\section{Germination of geosporous species}

Germination was tightly cued to fire in the majority of geosporous species with smoke providing the principal germination cue. The heat pulse acted as an alternative, though less effective, cue for two species (L. elimense and L. thymifolium, Fig. 1, Table S7). Heat and smoke can be distributed patchily during a fire (Auld and Bradstock 1996) and the ability to respond to more than one germination cue has been suggested to maximise the capability of seeds to sense the passage of fire (Kenny 2000). This may be especially important for non-resprouters that rely exclusively on postfire seedling recruitment for population persistence.

Imbibition tests showed all seed types were water-permeable, including those that responded to heat (Table S1), and, therefore, physical dormancy is not a feature of this genus (Baskin and Baskin 2014). The mechanism by which heat promotes germination of hard water-impermeable/physically dormant seeds has been well studied, but its mode of action on water-permeable seeds, such as Leucadendron, has received less attention. In the closely related genus, Leucospermum, dormancy is imposed by the water-permeable testa restricting oxygen diffusion to the embryo (Brits 1986b). The heat pulse from a fire is thought to alleviate dormancy via desiccation scarification of the testa (Brits et al. 1993; Brits and Manning 2019) and this is consistent with reports of a positive correlation between fire severity, via 
increased diurnal range of temperatures, and postfire seedling densities in Leucospermum conocarpodendron (Bond et al. 1990). Treatments that increase oxygen supply to the embryo, including scarification and high oxygen tensions, promote germination of Leucadendron daphnoides (Brown and van Staden 1973b). Heat responses in nut-fruited Leucadendron species might also cause alleviation of embryo anoxia in the same way but has yet to be examined. Our observation that smoke in the absence of heat was highly effective in promoting germination of the two heat-responsive Leucadendron species, but not for Leucospermum species (Brown and Botha 2004), indicates that the mechanisms of physiological dormancy between these genera do differ.

Two exceptions to the clear pattern of fire-dependent germination in species with soil-stored seeds were the uncertain effects of heat and smoke on $L$. tinctum and L. chamalaea (Fig. 2, Table S6). The relatively low overall germination of L. tinctum (Fig. 1) was possibly due to incomplete alleviation of physiological dormancy and/or application of suboptimal germination cues. In contrast to the present study, Brown and Botha (2004) reported smoke-enhanced germination in this species of $25-62 \%$ cf the controls, although no estimates of uncertainty were provided. They also reported that combined smoke and scarification improved germination by $25 \%$ cf smoke alone, but that improvement was negligible (6\%) with combined heat and smoke $c f$ smoke alone. An increase of germination by $20 \%$ following heat treatment was observed by Williams (1972). Germination of the controls in each of these trials was 12-35\%, suggesting that germination of $L$. tinctum could, in fact, be fire cue-dependent rather than fire cue-enhanced or fire cue-independent. In $L$. chamalaea, germination of the control (subjected to a summer postfire after-ripening treatment and incubated at autumn postfire temperatures) was unexpectedly high for a geosporous species [85\% (61\%, 99\%), Fig. 1]. Mosime (2016) reported substantial (up to 40-50\%) increases in germination of $L$. chamalaea with smoke; however, this was relative to $40 \%$ germination of $10{ }^{\circ} \mathrm{C}$ and $25{ }^{\circ} \mathrm{C}$ constant temperature controls, suggesting our use of diurnal alternating temperatures might have obviated the need for smoke as an alternative cue.

Both $L$. tinctum and $L$. chamalaea are geosporous nonresprouters that rely on seedling recruitment for postfire persistence. A period of in situ burial is sometimes required before seeds become responsive to fire cues (Roche et al. 1997; Baker et al. 2005; Newton et al. 2006) and this is worthy of further research. Additionally, ex situ storage might have unmonitored effects on dormancy and germination responses (Baskin et al. 2006); hence, caution is required when interpreting small or uncertain effects of fire cues observed among ex situ stored seeds. Possible explanations for this discrepancy include differences in the level of primary dormancy, seed age and storage effects, and interaction effects between smoke and temperature (Mackenzie et al. 2016). Further research is needed to resolve these disparate results, including examining other species with large nutlets that may remain dormant during cool fire cycles (noted by Bond et al. 1990).

The present study focussed on germination in the postfire environment and the role of cues directly associated with the passage of fire (i.e. heat pulse and smoke). However, germination of some species may be promoted to a greater or lesser extent by the indirect effects of fire, which would aid competition avoidance by restricting germination to the postfire environment or to canopy gaps in unburnt vegetation. Increased temperature fluctuations can impact seeds over summer (where there is potential for dry after-ripening) as well as over autumn and winter (while seeds are imbibed). Establishing the role of increased temperature fluctuations during these different seasons in Leucadendron seed germination requires a comparison of germination responses at under-canopy temperatures with those at gap/postfire temperatures. Nevertheless, all 30 serotinous species, except $L$. linifolium (97\%), showed potential for substantial germination in canopy gaps in unburnt fynbos (as indicated by germination of the controls) compared with one (11\%) geosporous species, L. chamalaea (Figs. 1, 2, Table S6). However, the potential for such germination to result in successful seedling recruitment is low (Bond 1984), with Banksia serrata a notable exception (Whelan et al. 1998). The few seedlings that do survive are usually starved of resources and remain depauperate (BBL, RMC, personal observations); fitness depends on survival and subsequent fecundity, not just on germination in the absence of disturbance (Lamont et al. 2019).

\section{Comparing germination responses and detecting treatment effects}

It is clear in this discussion that within species, very different germination results have sometimes been obtained in different studies. Identifying the possible cause of disparate results is tricky, as a multitude of factors that affect variability in primary seed dormancy and viability, both within and between populations and over time, such as maternal effects and phenotypic plasticity, are virtually impossible to predict and control. Furthermore, differing study aims result in different control, pre-treatment and germination conditions being chosen: those selected for an ecological study are likely to differ substantially from a horticultural study attempting to maximize seed germination in the shortest possible time. Finally, conditions during storage and germination affect seed vigour and viability and consequently germination outcomes. It is vital that future studies record and report these factors known to affect seed dormancy and germination (both total and rate), and consider possible 
interactions, to enable better interpretation of seed germination responses in an ecological context.

Finally, we comment on our approach to identifying important treatment effects. Despite widespread criticism of NHST, it continues to be routinely applied in seed science research to infer the existence of substantive effects on the sole basis of 'statistical significance' and, conversely (and erroneously), to infer the non-existence of such effects when faced with non-significant results. Even less desirable is the diagnosis of treatment effects based on point estimates alone while ignoring precision. Here, we advocate a more robust and informative approach as follows, in which: (i) both the magnitude and uncertainty of treatment effects are explicitly acknowledged and reported; (ii) consideration is given to the minimum effect size of biological consequence; and (iii) the importance of an effect is interpreted on the basis of its magnitude relative to the total germination response.

In this study, we regarded a change in germination of \pm 10 percentage points as the minimum meaningful effect. By explicitly acknowledging the uncertainty in our estimates and requiring at least $95 \%$ confidence to discern non-trivial from trivial effects, 16 (34\%) of the credibly non-zero effects identified in pairwise contrasts (those with 95\% HDIs excluding zero; analogous but not equivalent to 'statistically significant' in NHST) were too imprecisely estimated to reach a clear decision (Fig. S1, Table S7). Where non-trivial heat and smoke effects were identified, background (control) germination responses were used to evaluate their relative importance and distinguish supplementary cues from the principal drivers of postfire germination. Furthermore, 92 effects $(70 \%)$ with zero among their credible values were assessed as biologically trivial (the remaining $30 \%$ were too imprecisely estimated to classify either way). These results highlight the utility of Bayesian estimation and the importance of differentiating substantive from statistical significance. While the critical values for the minimum nonnegligible effect size and the required degree of confidence will vary between objectives and researcher proclivities, the subjective element can never be eliminated from interpreting data. Greater focus on parameter magnitudes and uncertainty will vastly improve confidence in the biological significance of the results obtained in future germination studies.

\section{Conclusions}

This comprehensive study on seed germination requirements of 40 Leucadendron species has shown that the most important predictor of germination syndromes in this important fynbos genus is seed storage location (serotinous vs geosporous) followed by seed morphology (winged achenes vs nutlets). Fires at moderate intervals are essential for (i) releasing the seeds of serotinous species onto an optimal seedbed for germination and recruitment but rarely contribute to their germination, and (ii) stimulating high levels of germination of geosporous species via smoke as they are water-permeable while fire-type heat is sometimes beneficial, possibly as a failsafe mechanism. These findings, in conjunction with established knowledge, such as a low (alternating) temperature requirement for germination, can be used to inform horticultural and endangered-species programs on propagation requirements for conservation and restoration purposes. These results have considerable generality as their wide range covers most likely outcomes among sclerophyll shrubs in South Africa and Australia in particular, but the unexpected exceptions documented here highlight the merit in examining the particular germination requirements of all species under consideration in more detail. Finally, this study highlights the importance of the following: (1) considered study design, including meaningful controls, particularly for understanding seed germination in an ecological context; (2) explicitly reporting factors that affect seed dormancy and germination to enable valid study comparisons; and, (3) using appropriate statistical methods for identifying biologically meaningful responses in seed germination studies.

Supplementary Information The online version contains supplementary material available at https://doi.org/10.1007/s00442-021-04947-2.

Acknowledgements We thank Ross Turner and SANBI (Kirstenbosch National Botanical Garden) for collection of seeds, Victoria Wilman for early collaboration, Katherine Downes for advice on methodology, Nicola Keogh and John Adams for laboratory support, and several colleagues, especially Tony Rebelo, for commenting on an earlier version of this manuscript.

Author contribution statement BBL, TH and RMC conceived the project and BBL, TH, RMC and RJN designed the experiments. PGB performed all experiments and tests. BDEM developed the approach to biological significance. BDEM (Figs 1, 2; Table 1, S2-S7), RJN and BBL (Table 1) analysed the data. TH tested phylogenetic independence. RJN, BDEM and BBL wrote the manuscript. Other authors contributed to drafts and gave final approval for publication.

Funding This research was supported by the Australian Research Council (projects DP120013389, DP130103029) and the BenthamMoxon Trust. The Royal Botanic Gardens, Kew, receives grant-in-aid from Defra, UK.

Availability of data and materials The datasets used and/or analysed during the current study are available from BDEM on reasonable request.

\section{Declarations}

Conflict of interest The authors declare that they have no conflict of interest.

Ethical approval This article does not contain any studies with human participants or animals performed by any of the authors. 
Open Access This article is licensed under a Creative Commons Attribution 4.0 International License, which permits use, sharing, adaptation, distribution and reproduction in any medium or format, as long as you give appropriate credit to the original author(s) and the source, provide a link to the Creative Commons licence, and indicate if changes were made. The images or other third party material in this article are included in the article's Creative Commons licence, unless indicated otherwise in a credit line to the material. If material is not included in the article's Creative Commons licence and your intended use is not permitted by statutory regulation or exceeds the permitted use, you will need to obtain permission directly from the copyright holder. To view a copy of this licence, visit http://creativecommons.org/licenses/by/4.0/.

\section{References}

Auld TD, Bradstock RA (1996) Soil temperatures after the passage of a fire: do they influence the germination of buried seeds? Aust J Ecol 21:106-109. https://doi.org/10.1111/j.1442-9993.1996. tb00589.x

Bååth R (2014) Bayesian first aid: a package that implements Bayesian alternatives to the classical *.test functions in $\mathrm{R}$, in the Proceedings of UseR! 2014 The International R User Conference. https:// github.com/rasmusab/bayesian_first_aid

Baker KS, Steadman KJ, Plummer JA, Merritt DJ, Dixon KW (2005) Dormancy release in Australian fire ephemeral seeds during burial increases germination response to smoke water or heat. Seed Sci Res 15:339-348. https://doi.org/10.1079/SSR2005222

Baskin CC, Baskin JM (2003) When breaking seed dormancy is a problem. Native Plants J 4:17-21. https://doi.org/10.3368/npj.4.1.17

Baskin CC, Baskin JM (2014) Seeds: ecology, biogeography and evolution of dormancy and germination, 2nd edn. Academic Press, San Diego

Baskin CC, Thompson K, Baskin JM (2006) Mistakes in germination ecology and how to avoid them. Seed Sci Res 16:165-168. https:// doi.org/10.1079/SSR2006247

Bell DT, Williams DS (1998) Tolerance of thermal shock in seeds. Aust J Bot 46:221-223. https://doi.org/10.1071/BT97010

Bergh NG, Verboom GA, Rouget M, Cowling RM (2014) Vegetation types of the greater Cape Floristic Region. In: Allsopp N, Colville JF, Verboom GA (eds) Fynbos: ecology, evolution and conservation of a megadiverse region. Oxford University Press, Oxford, pp $1-25$

Bond WJ (1984) Fire survival of Cape Proteaceae: influence of fire season and seed predators. Vegetatio 56:65-74

Bond WJ (1985) Canopy-stored seed reserves (serotiny) in Cape Proteaceae. S Afr J Bot 51:181-186. https://doi.org/10.1016/S02546299(16)31669-6

Bond WJ, Slingsby P (1983) Seed dispersal by ants in shrublands of the Cape Province and its evolutionary implications. S Afr J Sci 79:231-233

Bond WJ, Le Roux D, Erntzen R (1990) Fire intensity and regeneration of myrmecochorous Proteaceae. S Afr J Bot 56:326-330. https:// doi.org/10.1016/S0254-6299(16)31060-2

Bradstock RA, Gill AM, Hastings SM, Moore PHR (1994) Survival of serotinous seedbanks during bushfires: Comparative studies of Hakea species from southeastern Australia. Aust J Ecol 19:276282. https://doi.org/10.1111/j.1442-9993.1994.tb00490.x

Brits GJ (1986a) The effect of hydrogen peroxide treatment on germination in Proteaceae species with serotinous and nut-like achenes. S Afr J Bot 52:291-293. https://doi.org/10.1016/s0254-6299(16) 31523-x

Brits GJ (1986b) Influence of fluctuating temperatures and $\mathrm{H}_{2} \mathrm{O}_{2}$ treatment on germination of Leucospermum cordifolium and Serruria florida (Proteaceae) seeds. S Afr J Bot 52:286-290. https://doi. org/10.1016/S0254-6299(16)31522-8

Brits GJ (1987) Germination depth vs. temperature requirements in naturally dispersed seeds of Leucospermum cordifolium and $L$. cuneiforme (Proteaceae). S Afr J Bot 53:119-124. https://doi.org/ 10.1016/S0254-6299(16)31445-4

Brits GJ, Manning JC (2019) Seed structure and physiology in relation to recruitment ecology in Leucospermum (Proteaceae) in fynbos. Aust J Bot 67:290-308. https://doi.org/10.1071/BT18199

Brits GJ, Calitz FJ, Brown NAC, Manning JC (1993) Desiccation as the active principle in heat-stimulated seed germination of Leucospermum R. Br. (Proteaceae) in fynbos. New Phytol 125:397-403. https://doi.org/10.1111/j.1469-8137.1993.tb03892.x

Brown NAC (1993) Promotion of germination of fynbos seeds by plant-derived smoke. New Phytol 123:575-583. https://doi.org/ 10.1111/j.1469-8137.1993.tb03770.x

Brown NAC, Botha PA (2004) Smoke seed germination studies and a guide to seed propagation of plants from the major families of the Cape Floristic Region, South Africa. S Afr J Bot 70:559-581. https://doi.org/10.1016/S0254-6299(15)30194-0

Brown NAC, Dix L (1985) Germination of the fruits of Leucadendron tinctum. S Afr J Bot 51:448-452. https://doi.org/10.1016/S02546299(16)31623-4

Brown NAC, van Staden J (1971) Germination inhibitors in aqueous seed extracts of four South African Proteaceae. J S Afr Bot 37:305-315

Brown NAC, van Staden J (1973a) The effect of stratification on the endogenous cytokinin levels of seed of Protea compacta and Leucadendron daphnoides. Physiol Plant 28:388-392. https:// doi.org/10.1111/j.1399-3054.1973.tb08576.x

Brown NAC, van Staden J (1973b) The effect of scarification, leaching, light, stratification, oxygen and applied hormones on germination of Protea compacta $\mathrm{R}$.Br. and Leucadendron daphnoides Meisn. S Afr J Bot 39:185-195

Brown CL, Whelan RJ (1998) The role of Callistemon fruits and infructescences in protecting seeds from heat in fires. Aust $\mathrm{J}$ Bot 46:235-239. https://doi.org/10.1071/BT97026

Brown NAC, van Staden J, Daws MI, Johnson T (2003) Patterns in the seed germination response to smoke in plants from the Cape Floristic Region, South Africa. S Afr J Bot 69:514-525. https:// doi.org/10.1016/S0254-6299(15)30289-1

Causley CL, Fowler WM, Lamont BB, He T (2016) Fitness benefits of serotiny in fire- and drought-prone environments. Plant Ecol 217:773-779. https://doi.org/10.1007/s11258-015-0552-y

Collette J, Ooi MKJ (2017) Germination ecology of the endangered species Asterolasia buxifolia (Rutaceae): smoke response depends on season and light. Aust J Bot 65:283-291. https:// doi.org/10.1071/BT17025

Cowling RM, Holmes PM (1992) Flora and vegetation. In: Cowling RM (ed) The ecology of fynbos: nutrients, fire and diversity. Oxford University Press, Cape Town, pp 23-61

Dixon KW, Roche S, Pate JS (1995) The promotive effect of smoke derived from burnt native vegetation on seed germination of Western Australian plants. Oecologia 101:185-192. https://doi. org/10.1007/BF00317282

Downes KS, Light ME, Posta M, van Staden J (2015) Fire-related cues and the germination of eight Conostylis (Haemodoraceae) taxa, when freshly collected, after burial and after laboratory storage. Seed Sci Res 25:286-298. https://doi.org/10.1017/ S0960258515000227

Enright NJ, Marsula R, Lamont BB, Wissel C (1998) The ecological significance of canopy seed storage in fire-prone environments: a model for non-sprouting shrubs. J Ecol 86:946-959. https:// doi.org/10.1046/j.1365-2745.1998.00312.x

Enright NJ, Mosner E, Miller BP, Johnson N, Lamont BB (2007) Soil versus canopy seed storage and plant species coexistence 
in species-rich Australian shrublands. Ecology 88:2292-2304. https://doi.org/10.1890/06-1343.1

Gelman A, Meng X-L, Stern H (1996) Posterior predictive assessment of model fitness via realized discrepancies. Stat Sin 6:733-807

Ghosh J, Li Y, Mitra R (2018) On the use of Cauchy prior distributions for Bayesian logistic regression. Bayesian Anal 13:359383. https://doi.org/10.1214/17-BA1051

Gómez-González S, Paula S, Cavieres LA, Pausas JG (2017) Postfire responses of the woody flora of Central Chile: Insights from a germination experiment. PLoS ONE 12:1-12. https://doi.org/ 10.1371/journal.pone.0180661

Hall SA, Newton RJ, Holmes PM, Gaertner M, Esler KJ (2017) Heat and smoke pre-treatment of seeds to improve restoration of an endangered Mediterranean climate vegetation type. Austral Ecol 42:354-366. https://doi.org/10.1111/aec.12449

Hanley ME, Lamont BB (2000) Heat pre-treatment and the germination of soil- and canopy-stored seeds of south-western Australian species. Acta Oecol 21:315-321. https://doi.org/10.1016/ S1146-609X(00)01087-0

He T, Lamont BB, Manning J (2016) A Cretaceous origin for fire adaptations in the Cape flora. Sci Rep 6:1-6. https://doi.org/ 10.1038/srep34880

Heelemann S, Daniels F, Rebelo AG, Poschlod P, Reisch C (2013) Conservation genetics of Leucadendron argenteum (Silvertree): a flag ship species of the Cape Peninsula. S Afr J Bot 88:361366. https://doi.org/10.1016/j.sajb.2013.08.014

Holmes PM, Newton RJ (2004) Patterns of seed persistence in South African fynbos. Plant Ecol 172:143-158. https://doi.org/10. 1023/B:VEGE.0000026035.73496.34

Keeley JE, Bond WJ (1997) Convergent seed germination in South African fynbos and Californian chaparral. Plant Ecol 133:153-167

Keeley JE, Pausas JG, Rundel PW, Bond WJ, Bradstock RA (2011) Fire as an evolutionary pressure shaping plant traits. Trends Plant Sci 16:406-411. https://doi.org/10.1016/j.tplants.2011.04.002

Kenny BJ (2000) Influence of multiple fire-related germination cues on three Sydney Grevillea (Proteaceae) species. Austral Ecol 25:664-669. https://doi.org/10.1046/j.1442-9993.2000.01066.x

Kraaij T, van Wilgen BW (2014) Drivers, ecology, and management of fire in fynbos. In: Allsopp N, Colville JF, Verboom GA (eds) Fynbos: ecology, evolution and conservation of a megadiverse region. Oxford University Press, Oxford, pp 47-72

Kruschke JK (2018) Rejecting or accepting parameter values in Bayesian estimation. Adv Methods Pract Psychol Sci 1:270-280. https:// doi.org/10.1177/2515245918771304

Kruschke JK, Aguinis H, Joo H (2012) The time has come: Bayesian methods for data analysis in the organizational sciences. Organ Res Methods 15:722-752. https://doi.org/10.1177/1094428112 457829

Lamont BB, Enright NJ (2000) Adaptive advantages of aerial seed banks. Plant Sp Biol 15:157-166. https://doi.org/10.1046/j.14421984.2000.00036.x

Lamont BB, He T (2012) Fire-adapted Gondwanan Angiosperm floras evolved in the Cretaceous. BMC Evol Biol 12:223. https://doi.org/ $10.1186 / 1471-2148-12-223$

Lamont BB, He T (2017) Fire-proneness as a prerequisite for the evolution of fire-adapted traits. Trends Plant Sci 22:278-288. https:// doi.org/10.1016/j.tplants.2016.11.004

Lamont BB, Milberg P (1997) Removal of the testa during germination or establishment increases germinant mortality, decay and water loss. Seed Sci Res 7:245-252. https://doi.org/10.1017/S0960 258500003597

Lamont BB, Witkowski ETF, Enright NJ (1993) Post-fire litter microsites: safe for seeds, unsafe for seedlings. Ecology 74:501-512. https://doi.org/10.2307/1939311
Lamont BB, He T, Yan Z (2019) Evolutionary history of fire-stimulated resprouting, flowering, seed release and germination. Biol Rev 94:903-928. https://doi.org/10.1111/brv.12483

Lamont BB, Pausas JG, He T, Witkowski ETF, Hanley ME (2020) Fire as a selective agent for both serotiny and nonserotiny over space and time. Crit Rev Plant Sci 39:140-172. https://doi.org/10.1080/ 07352689.2020 .1768465

Lecoutre B, Lecoutre M, Poitevineau J (2001) Uses, abuses and misuses of significance tests in the scientific community: won't the Bayesian choice be unavoidable? Int Stat Rev 69:399-417. https:// doi.org/10.1111/j.1751-5823.2001.tb00466.x

Luna B (2020) Fire and summer temperatures work together breaking physical seed dormancy. Sci Rep 10:1-10. https://doi.org/10.1038/ s41598-020-62909-9

Mackenzie BDE, Auld TD, Keith DA, Hui FKC, Ooi MKJ (2016) The effect of seasonal ambient temperatures on fire-stimulated germination of species with physiological dormancy: A case study using Boronia (Rutaceae). PLoS ONE 11:e0156142. https://doi.org/10. 1371/journal.pone. 0156142

Midgley JJ, Enright NJ (2000) Serotinous species show correlation between retention time for leaves and cones. J Ecol 88:348-351. https://doi.org/10.1046/j.1365-2745.2000.00451.x

Midgley JJ, Viviers M (1990) The germination of seeds from heated serotinous cones of eight shrubland species. S Afr J 155:5-9. https://doi.org/10.1080/00382167.1990.9629064

Midgley JJ, Anderson B, Bok A, Fleming T (2002) Scatter-hoarding of Cape Proteaceae nuts by rodents. Evol Ecol Res 4:623-626

Midgley JJ, White JDM, Johnson SD, Bronner GN (2015) Faecal mimicry by seeds ensures dispersal by dung beetles. Nat Plants 1:15141. https://doi.org/10.1038/nplants.2015.141

Moreira B, Tormo J, Estrelles E, Pausas JG (2010) Disentangling the role of heat and smoke as germination cues in Mediterranean Basin flora. Ann Bot 105:627-635. https://doi.org/10.1093/aob/ mcq017

Mosime B (2016) In vitro conservation of selected endangered plant species indigenous to the Cape Floristic Region, South Africa. Masters Thesis, Faculty of Applied Sciences, Cape Peninsula University of Technology, Cape Town, South Africa.

Mustart PJ, Cowling RM (1993) The role of regeneration stages in the distribution of edaphically restricted fynbos Proteaceae. Ecol 74:1490-1499. https://doi.org/10.2307/1940077

Mustart PJ, Cowling RM, Dunne TT (1994) Reproductive traits of two closely related species-pairs on adjacent, different soil types in South African Fynbos. Vegetatio 111:161-171. https://doi.org/ 10.1007/BF00040335

Ne'eman G, Ne'eman R, Keith DA, Whelan RJ (2009) Does post-fire plant regeneration mode affect the germination response to firerelated cues? Oecologia 159:483-492. https://doi.org/10.1007/ s00442-008-1237-1

Newton RJ, Bond WJ, Farrant JM (2006) Effects of seed storage and fire on germination in the nut-fruited Restionaceae species, Cannomois virgata. S Afr J Bot 72:177-180. https://doi.org/10.1016/j. sajb.2005.05.005

Ooi MKJ, Auld TD, Denham AJ (2012) Projected soil temperature increase and seed dormancy response along an altitudinal gradient: implications for seed bank persistence under climate change. Plant Soil 353:289-303. https://doi.org/10.1007/ s11104-011-1032-3

Pérez-Fernández MA, Lamont BB, Marwick AL, Lamont WG (2000) Germination of seven exotic weeds and seven native species in southwestern Australia under steady and fluctuating water supply. Acta Oecol 21:323-336. https://doi.org/10.1016/S1146-609X(00) 01084-5

Plummer P (2013) JAGS: a program for analysis of Bayesian graphical models using Gibbs sampling. In: Proceedings of the $3 \mathrm{rd}$ 
international workshop on distributed statistical computing (DSC 2003), Vienna, Austria, 20-22 March. https://mcmc-jags.sourc eforge.io

Pons TL (1989) Breaking of seed dormancy by nitrate as a gap detection. Ann Bot 63:139-143. https://doi.org/10.1093/oxfordjournals. aob.a087716

Preston CA, Baldwin IT (1999) Positive and negative signals regulate germination in the post-fire annual, Nicotiana attenuata. Ecology 80:481-494. https://doi.org/10.1890/0012-9658(1999)080[0481: PANSRG]2.0.CO;2

R Core Team (2018) R: a language and environment for statistical computing. R Foundation for Statistical Computing, Vienna, Austria. https://www.R-project.org/

Rebelo T (2001) Proteas: a field guide to the proteas of Southern Africa, 2nd edn. Fernwood Press, Cape Town

Revell LJ (2012) Phytools: an R package for phylogenetic comparative biology (and other things). Methods Ecol Evol 3:217-223. https:// doi.org/10.1111/j.2041-210X.2011.00169.x

Roche S, Dixon KW, Pate JS (1997) Seed ageing and smoke: partner cues in the amelioration of seed dormancy in selected Australian native species. Aust J Bot 45:783-815. https://doi.org/10.1071/ BT96099

Rundel PW, Arroyo MTK, Cowling RM, Keeley JE, Lamont BB, Vargas P (2016) Mediterranean biomes: evolution of their vegetation, floras, and climate. Annu Rev Ecol Evol Syst 47:383-407. https:// doi.org/10.1146/annurev-ecolsys-121415-032330

Rusch UD, Midgley JJ, Anderson B (2013) Rodent consumption and caching behaviour selects for specific seed traits. S Afr J Bot 84:83-87. https://doi.org/10.1016/j.sajb.2012.09.007

SANBI (2017) Red list of South African plants version 2017.1. http:// redlist.sanbi.org/. Accessed 18 Nov 2019

Santana VM, Baeza MJ, Blanes MC (2013) Clarifying the role of fire heat and daily temperature fluctuations as germination cues for Mediterranean Basin obligate seeders. Ann Bot 111:127-134. https://doi.org/10.1093/aob/mcs238

Sauquet H, Weston PH, Anderson CL, Barker NP, Cantrill DJ, Mast AR, Savolainen V (2009) Contrasted patterns of hyperdiversification in Mediterranean hotspots. PNAS 106:221-225. https://doi. org/10.1073/pnas.0805607106

Schwab A, Abrahamson E, Starbuck WH, Fidler F (2011) Researchers should make thoughtful assessments instead of null-hypothesis significance tests. Organ Sci 22:1105-1120. https://doi.org/10. 1287/orsc. 1100.0557

Su Y, Yajima M (2015) R2jags: using R to run 'JAGS'. R-package version 0.05-01. https://cran.r-project.org/package $=\mathrm{R} 2$ jags

Thomas PB, Morris EC, Auld TD (2007) Response surfaces for the combined effects of heat shock and smoke on germination of 16 species forming soil seed banks in south-east Australia. Austral Ecol 32:605-616. https://doi.org/10.1111/j.1442-9993.2007. 01730.x
Thomas PB, Morris EC, Auld TD, Haigh AM (2010) The interaction of temperature, water availability and fire cues regulates seed germination in a fire-prone landscape. Oecologia 162:293-302. https:// doi.org/10.1007/s00442-009-1456-0

Thuiller W, Lavorel S, Midgley GF, Lavergne S, Rebelo AG (2004) Relating plant traits and species distributions along bioclimatic gradients for 88 Leucadendron taxa. Ecology 85:1688-1699. https://doi.org/10.1890/03-0148

Tonnabel J, Olivieri I, Mignot A, Rebelo AG, Justy F, Santoni S, Caroli S, Sauné L, Bouchez O, Douzery EJP (2014) Developing nuclear DNA phylogenetic markers in the angiosperm genus Leucadendron (Proteaceae): a next-generation sequencing transcriptomic approach. Mol Phylogenet Evol 70:37-46. https://doi.org/10. 1016/j.ympev.2013.07.027

Tonnabel J, Schurr FM, Boucher F, Thuiller W, Renaud J, Douzery EJP, Ronce O (2018) Life-history traits evolved jointly with climatic niche and disturbance regime in the genus Leucadendron (Proteaceae). Am Nat 191:220-234. https://doi.org/10.1086/ 695283

van Staden J, Brown NAC (1972) Characterization of germination inhibitors in seed extracts of four South African species of Proteaceae. J S Afr Bot 38:135-150

van Staden J, Brown NAC (1973) The effect of oxygen on endogenous cytokinin levels and germination of Leucadendron daphnoides seed. Physiol Plant 29:108-111. https://doi.org/10.1111/j.13993054.1973.tb04818.x

Wasserstein RL, Schirm AL, Lazar NA (2019) Moving to a world beyond $\mathrm{p}<0.05$. Am Stat 73(1):1-19. https://doi.org/10.1080/ 00031305.2019.1583913

Whelan RJ, De Jong NH, Von Der Burg S (1998) Variation in bradyspory and seedling recruitment without fire among populations of Banksia serrata (Proteaceae). Austral Ecol 23:121-128. https://doi.org/10.1111/j.1442-9993.1998.tb00710.x

Williams IJM (1972) A revision of the genus Leucadendron (Proteaceae). Contrib Bolus Herb 3:1-425

Williams PR, Congdon RA, Grice AC, Clarke PJ (2003) Fire-related cues break seed dormancy of six legumes of tropical eucalypt savannas in north-eastern Australia. Austral Ecol 28:507-514. https://doi.org/10.1046/j.1442-9993.2003.01307.x

Yan G, Croxford B, Sedgley R (2001) Interspecific hybridisation of Leucadendron. Acta Hortic 552:55-63. https://doi.org/10.17660/ ActaHortic.2001.552.5

Yearsley EM, Fowler WM, He T (2018) Does smoke water enhance seedling fitness of serotinous species in fire-prone southwestern Western Australia? S Afr J Bot 115:237-243. https://doi.org/10. 1016/j.sajb.2017.09.012

Zhao X, Ladd PG (2014) Seed germination and unusual serotiny in two species of Conospermum from fire-prone vegetation in Western Australia. Aust J Bot 62:511-517. https://doi.org/10.1071/BT142 37 